\title{
Stagnation Zone during the Turning of Duplex SAF 2205 Stainless Steels alloy
}

\author{
J. Nomani, A. Pramanik*, T. Hilditch, G. Littlefair \\ School of Engineering, Deakin University, Geelong, Australia \\ *Department of Mechanical Engineering, Curtin University, WA 6102, Australia
}

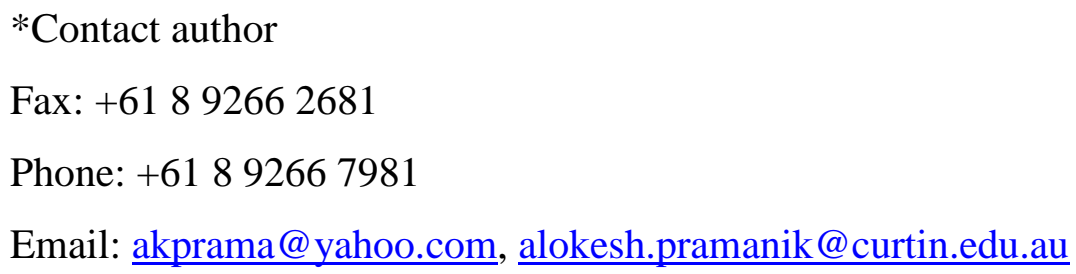

\begin{abstract}
.
Duplex stainless alloys are extremely sensitive to cutting speed for strain hardening during machining. Tool wear for these materials is dominated by the adhesion wear because of formation of built-up edge (BUE) which upsurges the flank wear considerably. In addition, flute damage is a significant problem during drilling of those alloys. To address this issue, this paper investigates the mechanism of BUE creation in stagnation region of duplex SAF 2205 alloys during material removal by turning process. The investigation of chip root through SEM and electron backscatter diffraction (EBSD) revealed build-up of ferritic bands at the stagnation zone. Higher capacity of austenite phase to deform plastically is accountable for the ferrite build-up. This was detected as a possible activating mechanism of built-up edge. The flow pattern of austenite phase designates faster deforming compare to that of ferrite phases.
\end{abstract}

Key words: duplex, stainless, steel, deformation, chip, stagnation zone, turning. 


\section{Introduction}

Duplex stainless steels (DSSs) have almost identical portion of austenite and ferrite phases after proper heat treatment $[1,2]$. There are many advantages of DDS, such as (i) higher strength than their ingredients [3,4], (ii) yield strength is double to that of austenitic grades (iii) highly ductile and tough [5], and (v) the effect of nickel price on the cost is less compare to austenitic stainless steel [6]. However, the affinity to generate BUE is very high during machining of DSS. This is happened due to attachment of the materials from workpiece to the faces of cutting tool which causes higher surface roughness, low control on dimensional tolerance and higher wear of cutting tools [7, 8]. It is known that austenite 316L has less tendency to form BUE compared to that of duplex SAF 2205 \& SAF 2507 alloys. This speeds up tool degradation and increases surface roughness during machining duplex alloys $[9,10]$. The tougher austenite phase scatters in the machining zone when softer ferrite phase is commendably pressed during the progression of the cutting tool. Tool wear was dominated by the adhesion process due to development of BUE which increases the flank wear significantly. In addition, flute damage was considered as a significant problem during drilling of those alloys. Duplex 2507 alloy is highly sensitive to cutting speed for strain hardening. The higher percentage of $\mathrm{Ni}, \mathrm{Mo}$ and $\mathrm{Cr}$ reduces the machinability of Duplex 2507[11]. There are many other investigations on machining of DSS, such as Paro et al. [12] found that the adhesion wear activated by BUE is the leading process of tool wear. Carlborg [13] blamed the higher percentage of ferrite in duplex stainless steel for frequent built-up edge without giving any mechanism behind it. Williams [14] stated that the materials with more than one phase, for example DSS, have two fracture points that arise along the interface of chip and rake face in the course of BUE generation, while materials with single phase uphold single rupture point.

The researches on machining of duplex stainless steel have mainly focused on the machinability aspect of these alloys [15-20]. There is almost no research to investigate the mechanisms of BUE formation during machining of duplex SAF 2205 stainless steels alloy. This investigation explores plastic deformation of SAF 2205 alloy in the stagnation zone during machining. The plastic deformation in this area can deliver understanding of recurrent occurrence BUE.

\section{Materials and methods}

Turning processes were performed with $0.2 \mathrm{~mm} / \mathrm{rev}$ feed and, 74 and $48 \mathrm{~m} / \mathrm{min}$ speed. Fig. 1 shows the quick-stop device that was applied to freeze chip roots at the designated machining condition. Trigon shaped WNMG-TF solid carbide inserts with $0^{\circ}$ clearance were used as cutting tool. The frozen chip roots were cut from the workpiece at low speed. These were then hot-mounted in PolyFast resin 
and grounded to investigate the microstructure of chip roots. This study focused on 'as received' condition $\varnothing 20 \mathrm{~mm}$ round-bar SAF 2205 alloy duplex grade whose compositions are shown in Table. 1.

OPS MD-Chem pad was used to polish all samples after achieving $1 \mu \mathrm{m}$ surface finish by MD-Mol pads. Beraha's tint etchant was then used to etch the samples only for structure study under high resolution SEM (LEO 1530 FEG-SEM) using a thermal field emission type gun. Beraha's tint etchant is made of $85 \mathrm{ml}$ water, $15 \mathrm{ml} \mathrm{HCl}, 1 \mathrm{~g} \mathrm{~K}_{2} \mathrm{~S}_{2} \mathrm{O}_{5}$. Scans were performed at high flow of electricity, working distance $10 \mathrm{~mm}$, aperture operating $60 \mu \mathrm{m}$ and accelerating voltage $20 \mathrm{kV}$. Samples were not etched for electron backscatter diffraction (EBSD) scans. EBSD scans were taken at high current, operating at $20 \mathrm{kV}$ using high resolution CCD detector at an insertion space of $176 \mathrm{~mm}$ and $70^{\circ}$ incline angle. Working space was varied from 8 to $12 \mathrm{~mm}$ with $60 \mu \mathrm{m}$ aperture size. Acquired maps were managed by 5 Channel HKL software and those were prepared at level 5 by $3 \mathrm{x}$ zero solutions.

\section{Results and discussion}

Fig. 2 shows the processed SAF 2205 DSS sample collected at $94 \mathrm{~m} / \mathrm{min}$ speed, $0.15 \mathrm{~mm} / \mathrm{rev}$ feed and $2.5 \mathrm{~mm}$ chip thickness. It is clear that the material passes through the shear zones and converted into the chip. Severe deformation occurs to both the austenite and ferrite phases at the entry points to the primary and secondary shear zones because of the high strain rate and strain. This elongates grains and tilts those into in the path of plastic flow which also indicates occurrences of work-hardening during this transition.

The preliminary growth of a BUE is noted in the stagnation zone which is located at the tool tip as shown in Fig. 2(b). The material in the stagnation zone remains stationary and no plastic flow occurs for a certain time. Leading ferrite build-up was visible in this area, though small visible austenite traces were present in the dead zone. In the outer region, highly elongated austenite grains appear to be banding away from this region. The stagnation zone from forward scatter detector (FSD) is presented in Fig. 3(a)-(c) where the highly distorted grains decrease the quality of electron backscatter diffraction pattern (EBSP). This makes the indexing of phase more problematic as the scanning drew nearer the interface between cutting tool and chip [21].

Phases in stagnation zone indicate a pool of ferrite stacking as shown in Fig. 4. The banded ferrite zone is highlighted in Fig. 4(a). This region appears squeezed with grains of ferrite and substructures, and it is likely for this band to accumulate in size if the tool was to continue in its cutting path. Beyond the ferrite band region, grain structures are no longer visible [22]. 
Grain boundary maps displayed in Fig. 5 highlight a substantial alteration grain size and orientation. It would appear that the high strain in the stagnation region caused phases to evolve into dense compact hetergeneous structures, also referrred to as lamellar boundaries. These are a amalgamation of grain boundaries of different angles which are compressed together to reform an complicated web of subgrains and grains. These grains typically form due to high strain [23], which is very common in machining operations. A common indicator of high dislocation activity is the presense of low angle grain boundaries (LAGB). Misorientation distributions were checked which show the population count of low angle grain boundaries for austenite and ferrite in the stagnation zone was higher compared to the original undeformed structure. These LAGB areas are ploted green and red (solid black and white lines in printed version) in Fig. 5(a) and (b) are largely concentrated inside subgrains. This distinguishies areas of large strain and deformation [24].

The incidence of annealing twins is very often in austenite phase and this is due to 'accidental' growth of grains under loading conditions. Sixty degree misorientation about the $<111>$ plane is noted for annealing twins. Studies have reported, the presense of annealing twins act as obstacle to the movement of slip [25]. Therefore, the absense of annealing twins would indicate an increase to the promotion of slip occuring in the austenite phase. Fig. 6 displays twin boundaries in the original as-received microstructure, and in the stagnation zone region, highlighted in blue (solid black line in printed version). The visible twin boundaries appear dismembered and scattered in the stagnation region.

It is most likely the high deformation occuring has caused the annealing twin boundaries to misorientate beyond sixty degree. Given that sixty degree is the highest misorientation angle of recognition in plane <111> since the illustration of lowermost angle is continually identified. Consequently, the borders of twins have structurally distorted and are identified at smaller misorientation angles. These borders of twins travel as shown in Fig. 6 and don't lie on sixty degree misorientation axis any longer.

The ferritic bands and micro-cracks at the stagnation region activates BUE apparently. It is suggested that high cyclic loading contributes the generation of these micro-cracks $[22,26,27]$. The cracks due to fatigue start ferritic slip bands very often during high cyclic fatigue loading. The material in the stagnation region does not moving though the chip formation and sliding of material continues [28]. Similarly, the shearing flow of material into the chip produces high cyclic loading environments. These initiate micro-crack which is the first stage of BUE formation. The activating process of these ferrite bands suggest that the higher amount of ferrite induces more BUE [13]. 
Austenite has denser dislocation than ferrite [29]. A high occurrence of low angle grain boundaries (LAGB) detected in both phases in the current study indicated a large amount of dislocation activity has occurred. The elongated austenite grains flow faster into the chip through the shear zones while the remaining austenite at the lower region remains embedded into the workpiece as the tool nose moving forward in its direction. The ferrite bands appear to be flowing in the similar directions to that of austenite, but at a slower rate. The elongated ferrite grains maintain more of the plastic strain as those are larger than austenite grains. Thus ferrite bands tend to collect at the stagnation zone as austenite flows faster than ferrite.

The activated slip systems explain the absence of twin boundaries. The dislocations activated by these slip systems would be enough to re-orientate these twin boundaries from its original orientation, in order to relieve the pile-up of stress concentrations, explaining the decline in twin boundary population at the stagnation region.

\section{Conclusion}

This paper explores the deformation process of DSS in the stagnation zone during turning. The following conclusions are drawn from investigations of chip roots:

- A collection of ferrite bands accumulating at the stagnation area are a trigger to the generation of BUE. Micro-cracks developing transgranular from the ferrite build-up, and developing past the chip-tool interface, traces similar profiles to micro-cracks starting BUE development.

- Higher capability of austenite to deform plastically, caused by high strain activating multiple slip systems, is responsible for the ferrite bands collecting at the stagnation region. The flow patterns show austenite is flowing faster into the chip or remaining in the workpiece region.

- The identification of heterogeneous lamellar structures and the re-orientation of annealing twins in austenite show dislocations are occurring by multiple slip systems. A single study should be conducted to determine the maximum strain value before multiple slip systems are activated in the austenite phase, in DSS alloys.

\section{References}

1. Davis, J.R., ASM specialty handbook: heat-resistant materials. 1997: Asm International.

2. Svensson, L.; Gretoft. B. Propertiesmicrostructure relationship for duplex stainless steel weld metals. in Proceedings. In: Conference Duplex Stainless Steels. 1986. 
3. Chen, L.; Tan, H.; Wang, Z.; Li, J.; Jiang, Y. Influence of cooling rate on microstructure evolution and pitting corrosion resistance in the simulated heat-affected zone of 2304 duplex stainless steels. Corrosion Science 2012, 58, 168-174.

4. Wang, S.-G.; Dong, G.-P.; Ma, Q.-H. Welding of duplex stainless steel composite plate: influence on microstructural development. Materials and Manufacturing Processes 2009, 24(12), 1383-1388.

5. Tan, H.; Wang, Z.; Jiang, Y.; Yang, Y.; Deng, B.; Song, H.; Li, J. Influence of welding thermal cycles on microstructure and pitting corrosion resistance of 2304 duplex stainless steels. Corrosion Science 2012, 55, 368-377.

6. Davison, R.; Redmond, J. A guide to using duplex stainless steels. Materials \& Design 1991, 12(4), 187-192.

7. Koyee, R. D.; Schmauder, S.; Heisel, U.; Eisseler, R. Numerical modeling and optimization of machining duplex stainless steels. Production \& Manufacturing Research 2015, 3(1), 36-83.

8. Krolczyk, G.; Nieslony, P.; Legutko, S. Determination of tool life and research wear during duplex stainless steel turning. Archives of Civil and Mechanical Engineering 2015, 15(2), 347354.

9. Nomani, J.; Pramanik, A.; Hilditch, T.; Littlefair, G. Machinability study of first generation duplex (2205), second generation duplex (2507) and austenite stainless steel during drilling process. Wear 2013, 304(1-2), 20-28.

10. Metelski, A.; Krile, S.; Maruda, R. W.; Legutko, S.; Krolczyk, G. M. Dynamic Programming Approach in the Optimization of Tool Life in Turning Process of Duplex Stainless Steel DSS. Key Engineering Materials 2016, 686, 143-148.

11. Nomani, J.; Pramanik, A.; Hilditch, T.; Littlefair, G. Chip formation mechanism and machinability of wrought duplex stainless steel alloys. International Journal of Advanced Manufacturing Technology 2015, 80(5), 1127-1135.

12. Paro, J.; Hänninen, H.; Kauppinen, V. Tool wear and machinability of HIPed P/M and conventional cast duplex stainless steels. Wear 2001, 249(3-4), 279-284.

13. Carlborg, C. Machinability of duplex stainless steel. Proceedings of duplex stainless steel 1991, $1(1), 683-96$.

14. Williams, J.E.; Rollason, E.C. Metallurgical and Practical Machining Parameters Affecting Built-up Edge Formation in Metal Cutting. Journal of the Institute of Metals 1970, 98, 144159. 
15. de Oliveira Junior, C.A.; Diniz, A.E.; Bertazzoli, R. Correlating tool wear, surface roughness and corrosion resistance in the turning process of super duplex stainless steel. Journal of the Brazilian Society of Mechanical Sciences and Engineering 2014, 36(4), 775-785.

16. Selvaraj, D.P.; Chandramohan, P.; Mohanraj, M. Optimization of surface roughness, cutting force and tool wear of nitrogen alloyed duplex stainless steel in a dry turning process using Taguchi method. Measurement 2014, 49, 205-215.

17. Krolczyk, G.; Legutko, S.; Stoić, A. Influence of cutting parameters and conditions onto surface hardness of duplex stainless steel after turning process. Tehnički vjesnik, 2013, 20(6), 1077-1080.

18. Koyee, R. D.; Heisel, U.; Schmauder, S.; Eisseler, R. Experimental Investigation and Multiobjective Optimization of Turning Duplex Stainless Steels. International Journal of Manufacturing Engineering 2014, 2014, 1-13

19. Krolczyk, G.; Nieslony, P.; Legutko, S.; Hloch, S.; Samardzic, I. Investigation of selected surface integrity features of Duplex Stainless Steel (DSS) after turning. Metalurgija 2015, 54(1), 91 94.

20. Krolczyk, G. M.; Maruda, R. W.; Nieslony, P.; Wieczorowski, M. Surface morphology analysis of Duplex Stainless Steel (DSS) in Clean Production using the Power Spectral Density. Measurement 2016, 94, 464-470.

21. Motoyashiki, Y.; Brückner-foit, A.; Sugeta, A. Investigation of small crack behaviour under cyclic loading in a dual phase steel with an FIB tomography technique. Fatigue \& Fracture of Engineering Materials \& Structures 2007, 30(6), 556-564.

22. Dönges, B.; Giertler, A.; Krupp, U.; Fritzen, C. P.; Christ, H. J. Significance of crystallographic misorientation at phase boundaries for fatigue crack initiation in a duplex stainless steel during high and very high cycle fatigue loading. Materials Science and Engineering: A 2014, 589, 146-152.

23. Hughes, D.A.; Hansen, N. High angle boundaries formed by grain subdivision mechanisms. Acta Materialia 1997, 45(9), 3871-3886.

24. Nomani, J.; Pramanik, A.; Hilditch, T.; Littlefair, G. Investigation on the Behavior of Austenite and Ferrite Phases at Stagnation Region in the Turning of Duplex Stainless Steel Alloys. Metallurgical and Materials Transactions A 2016, 47(6), 3165-3177.

25. Randle, V. Mechanism of twinning-induced grain boundary engineering in low stacking-fault energy materials. Acta Materialia 1999, 47(15-16), 4187-4196. 
26. Iwata, K.; Ueda, K. Fundamental analysis of the mechanism of built-up edge formation based on direct scanning electron microscope observation. Wear 1980, 60(2), 329-337.

27. Wallbank, J. Structure of built-up edge formed in metal cutting. Metals Technology 1979, 6(1), 145-153.

28. Nasr, M.N.A.; Ng, E.G.; Elbestawi, M.A. Modelling the effects of tool-edge radius on residual stresses when orthogonal cutting AISI 316L. International Journal of Machine Tools and Manufacture 2007, 47(2), 401-411.

29. Johansson, J.; Odén, M. Load sharing between austenite and ferrite in a duplex stainless steel during cyclic loading. Metallurgical and Materials Transactions A 2000, 31(6), 1557-1570. 
Table 1 Composition of SAF 2205 alloy (wt \%) [10]

\begin{tabular}{lllllllll}
\hline $\mathrm{C}$ & $\mathrm{Mn}$ & $\mathrm{Si}$ & $\mathrm{S}$ & $\mathrm{P}$ & $\mathrm{Ni}$ & $\mathrm{Cr}$ & $\mathrm{Mo}$ & $\mathrm{Fe}$ \\
\hline 0.02 & 0.8 & 0.4 & 0.01 & 0.02 & 5.2 & 22.4 & 3.05 & Balance \\
\hline
\end{tabular}

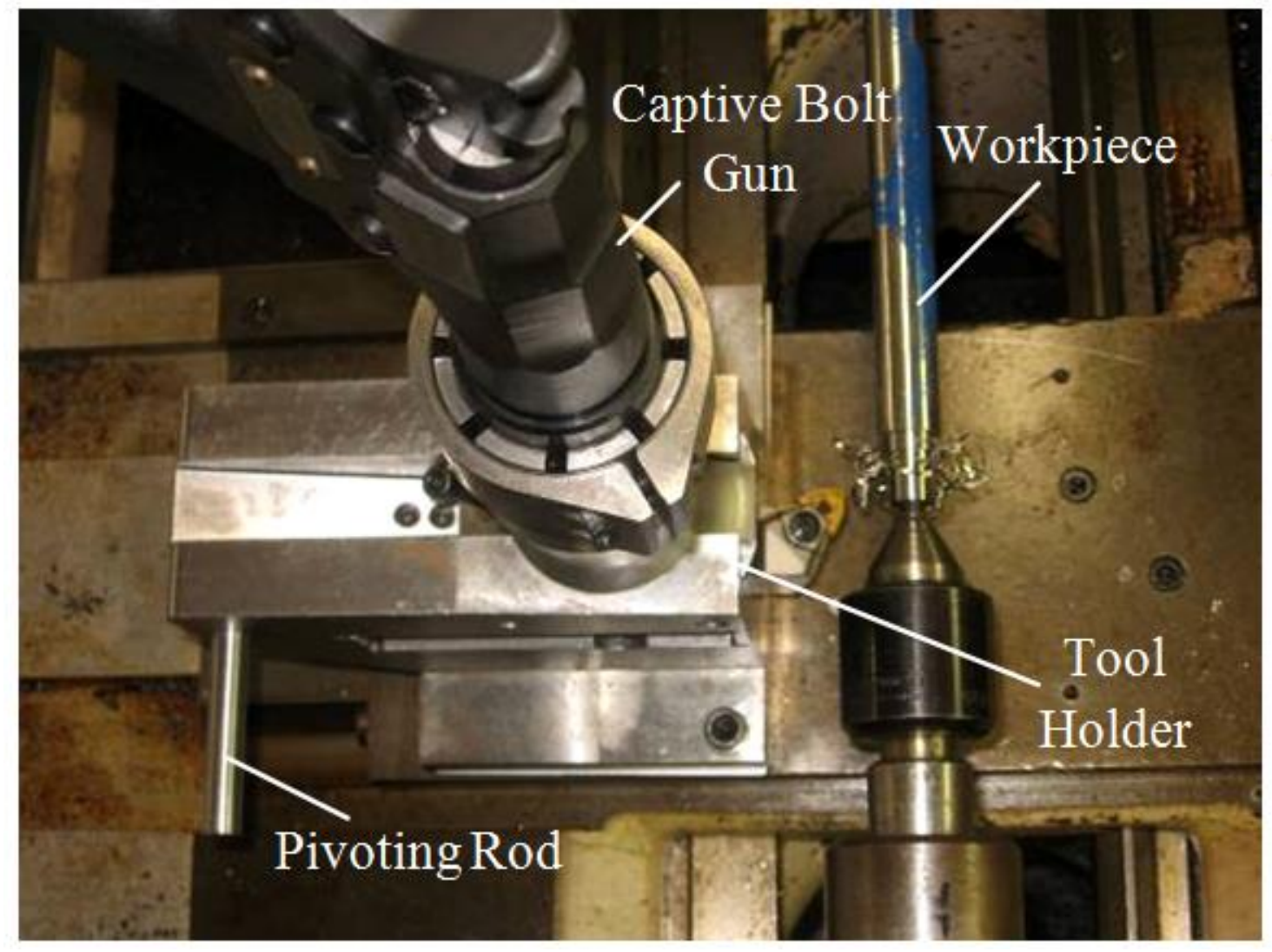

Fig. 1 Setup of quick-stop experiment 

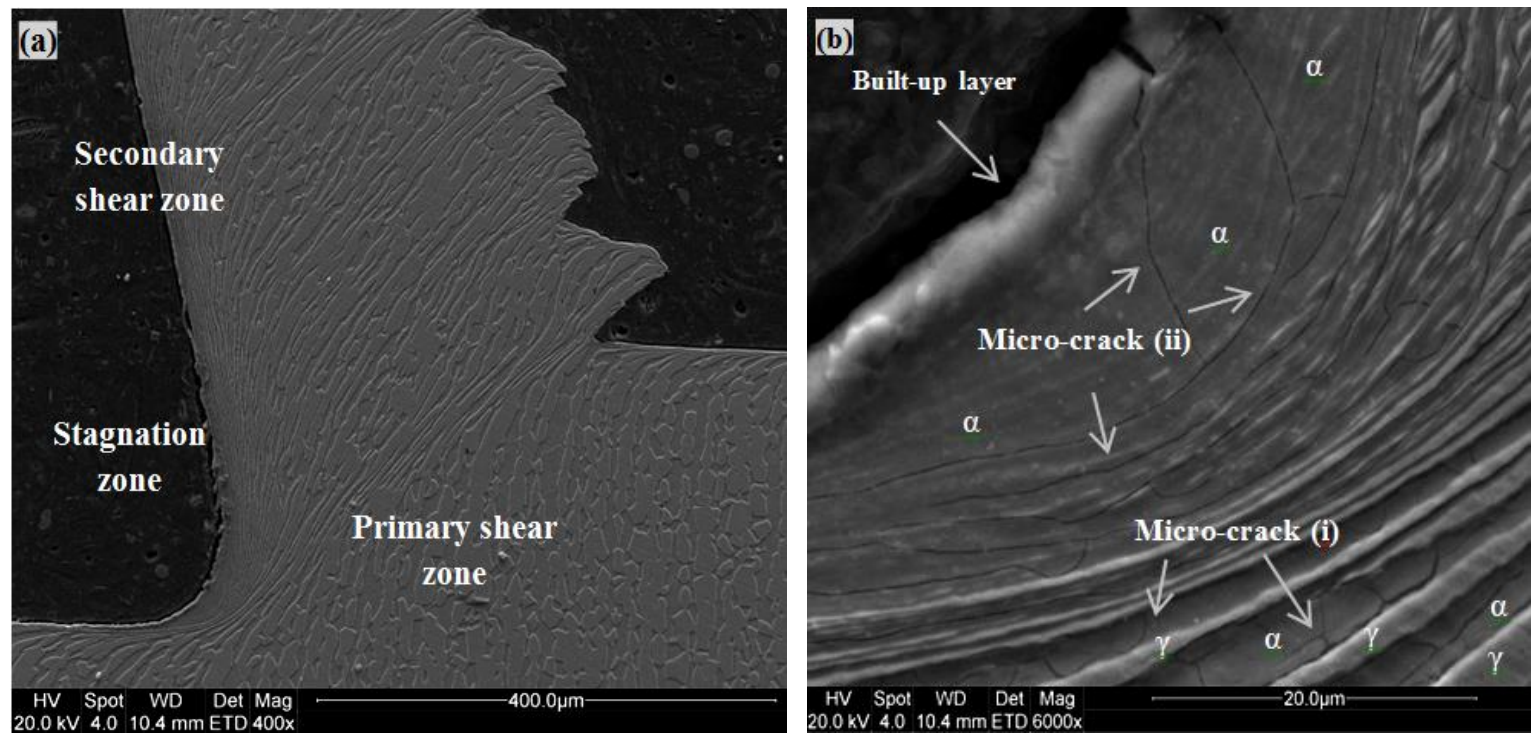

Fig. 2 Chips of SAF 2205 duplex steel at speed $94 \mathrm{~m} / \mathrm{min}$, feed $0.15 \mathrm{~mm} / \mathrm{rev}$, chip thickness $2.0 \mathrm{~mm}$ where $\alpha$-ferrite and $\gamma$-austenite phases (a) overview of chip (b) Magnified view of BUE [10].
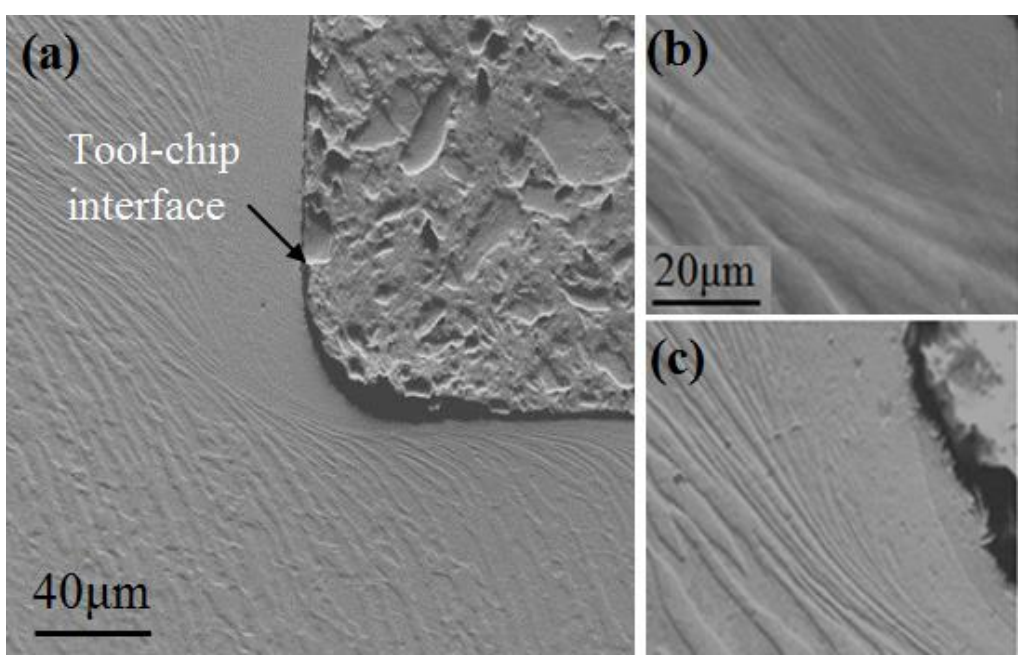

Fig. 3 FSD images for phase mapping of the stagnation zone (a) location of FSD scans on chip root sample at cutting speeds (b) $74 \mathrm{~m} / \mathrm{min}$ and (c) $48 \mathrm{~m} / \mathrm{min}$ with $0.2 \mathrm{~mm} / \mathrm{rev}$ feed 

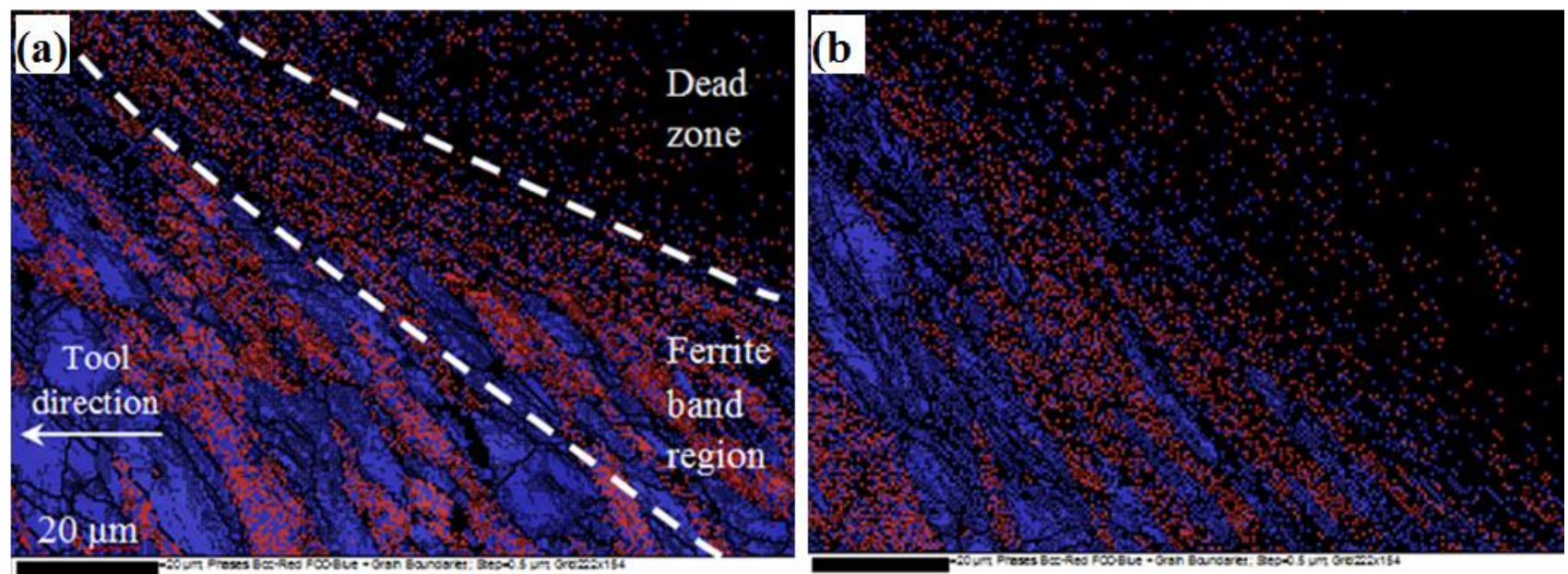

Fig. 4 Phases in the stagnation zone on chip root samples at different speed (a) $74 \mathrm{~m} / \mathrm{min}$ and (b) 48 $\mathrm{m} / \mathrm{min}$ at feed $=0.2 \mathrm{~mm} / \mathrm{rev}$ (colour map: ferrite red, austenite blue, non-index black).
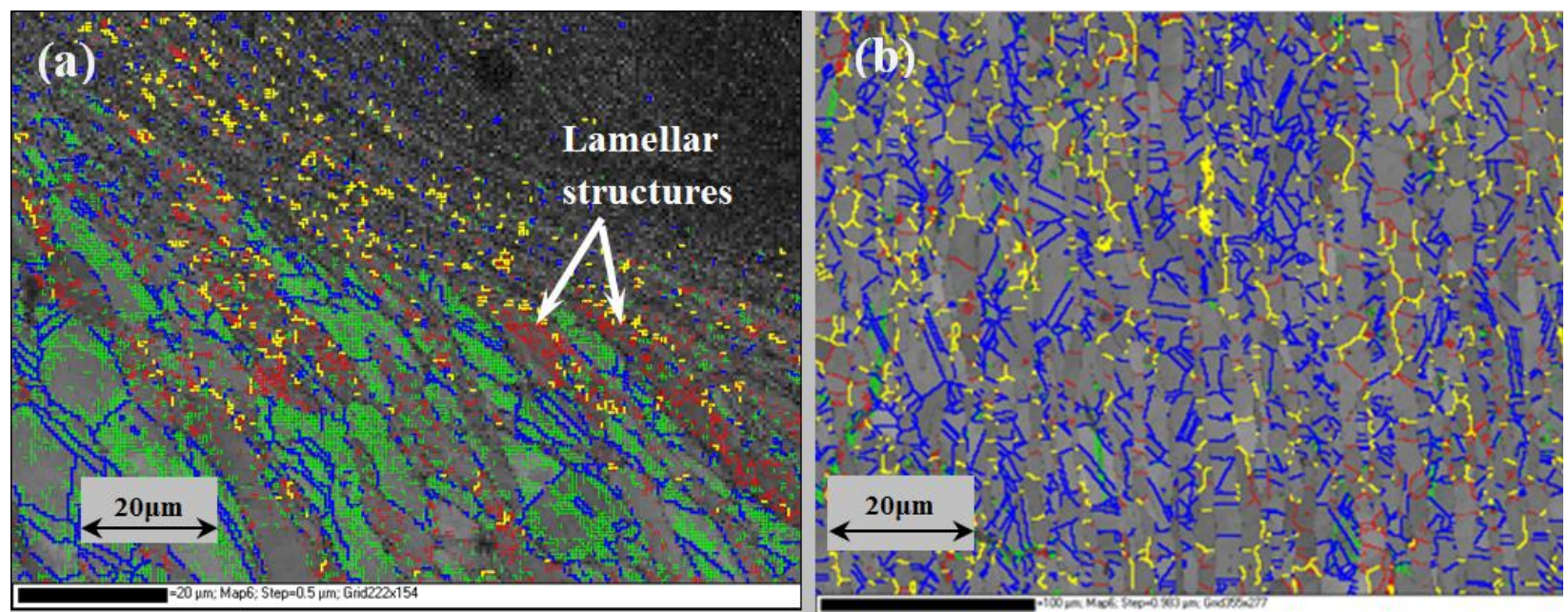

Fig. 5 Grain boundary in the stagnation zone (a) chip root microstructure at $1.00 \mathrm{kx}$ and (b) asreceived microstructure. Map and distribution colouring (austenite, LAGB green 2-10, HAGB blue $\left.>10^{\circ}\right)\left(\right.$ ferrite, $\mathrm{LAGB}$ red $2-10^{\circ}, \mathrm{HAGB}$ yellow $\left.>10^{\circ}\right)$ 


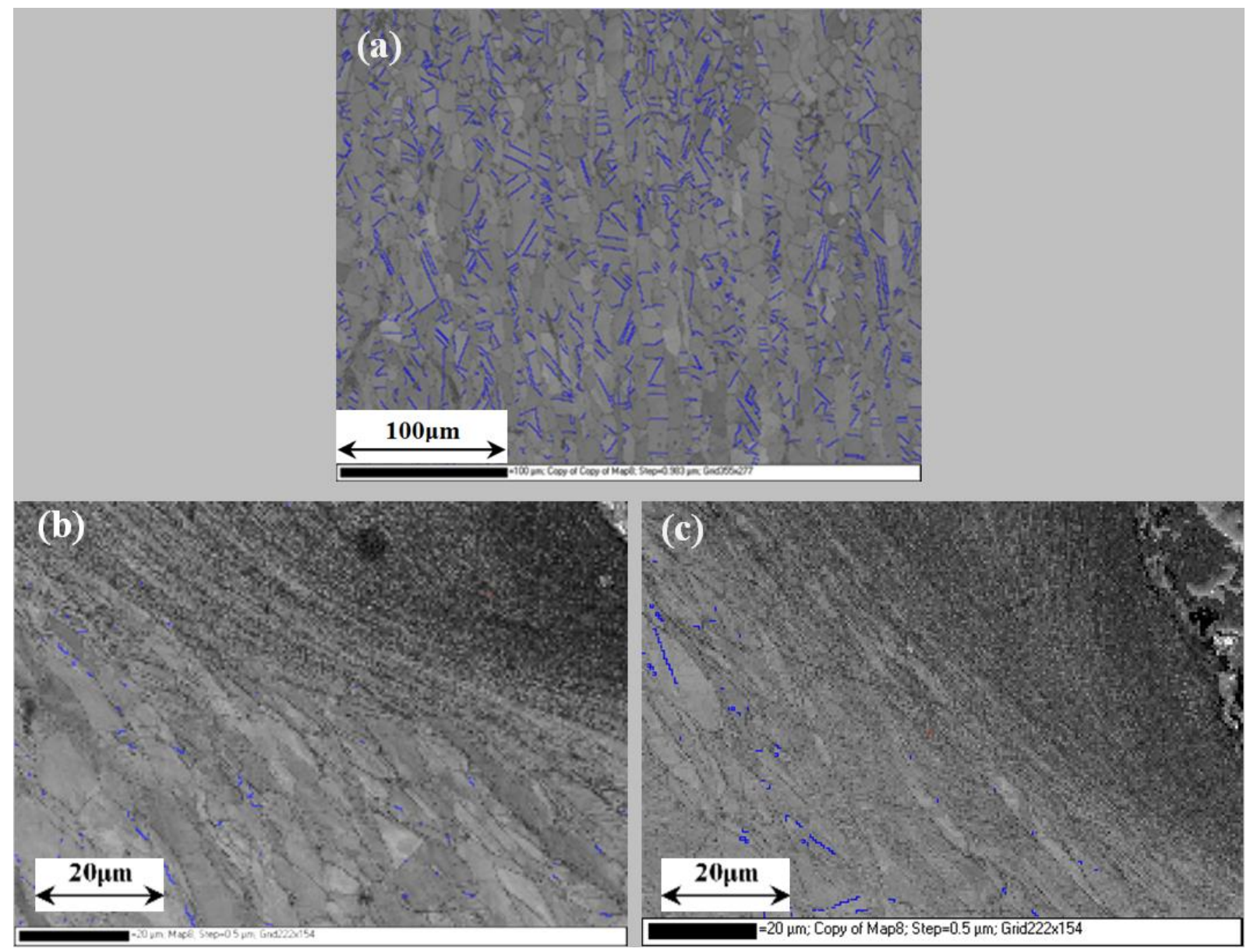

Fig. 6 Twin boundary map of (a) original SAF 2205 structure and stagnation zone samples chip root produced at (b) $75 \mathrm{~m} / \mathrm{min}$ (c) $48 \mathrm{~m} / \mathrm{min}$; mapping blue at $\left.60^{\circ}<111\right\rangle$ 